\title{
Standardized Antipyretic Treatment in Stroke: A Pilot Study
}

\author{
Bernd Kallmünzer Christiane Krause Elisabeth Pauli Alexander Beck \\ Lorenz Breuer Martin Köhrmann Rainer Kollmar \\ Department of Neurology, University Medical Center Erlangen-Nuremberg, Erlangen, Germany
}

\section{Key Words}

Stroke $\cdot$ Normothermia $\cdot$ Acute stroke care $\cdot$ Fever . Hyperthermia

\begin{abstract}
Background: Fever after acute cerebral injury is associated with unfavorable functional outcome and increased mortality, but there is controversy about the optimal antipyretic treatment. This study investigated an institutional standard operating procedure (SOP) for fever treatment in stroke patients including a sequence of pharmacologic and physical interventions. Methods: A 4-step antipyretic SOP was established for patients with acute cerebral ischemia or hemorrhage and a body temperature $\geq 37.5^{\circ} \mathrm{C}$ within the first 6 days after admission. Data on the course of body temperature, duration of fever and achievement of normothermia were recorded. Results were compared to a historic control group that underwent conventional treatment. Results: A total of 77 patients (mean age $70.4 \pm 14.2$ yeas) received 331 antipyretic interventions. Sequential administration of paracetamol $(n=219)$, metamizole $(n=71)$ and calf packing $(n=24)$ resulted in a significant drop in body temperature after $60 \mathrm{~min}$ in each instance. In 5 of 9 cases which were refractory to previous attempts, normothermia followed the infusion of ice-cooled saline. In more than $90 \%$ of cases treat-
\end{abstract}

ed per protocol, normothermia was achieved within 120 min. Compared to conventional treatment, fever burden was significantly lower within the first 4 days after admission $(p<0.001)$. Conclusion: This SOP may help to optimize antipyretic treatment for stroke patients.

Copyright $\odot 2011$ S. Karger AG, Basel

\section{Introduction}

Fever in patients with acute cerebral injury is associated with higher mortality, worse functional outcome and longer in-hospital and intensive care unit stays [1]. Up to $61 \%$ of patients with ischemic stroke suffer from fever within the first $48 \mathrm{~h}$ after symptom onset [2-4], and an observational study found elevated body temperatures following intracerebral hemorrhage in $91 \%$ of cases [5]. For each $1^{\circ} \mathrm{C}$ increase in body temperature, the relative risk for poor outcome may rise by a factor of 2.2 [6]. Therefore, effective antipyretic treatment should in theory translate to improved functional outcome and higher survival rates.

However, results from previous studies do not allow evidence-based recommendations for a specific antipyretic strategy [7]. A systematic review identified 5 trials using pharmacological approaches and 3 trials using

\section{KARGER \\ Fax +4161306 1234 E-Mail karger@karger.ch} www.karger.com

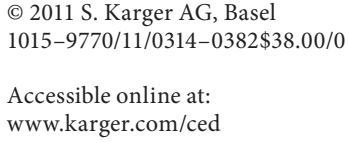

Bernd Kallmünzer, MD

Department of Neurology, University of Erlangen-Nuremberg

Schwabachanlage 6, DE-91054 Erlangen (Germany)

Tel. +499131854 4634, Fax +4991318536597

E-Mail bernd.kallmuenzer@uk-erlangen.de 
Fig. 1. The SOP. Fever was treated by following a sequence of 4 antipyretic interventions with close control of body temperature.

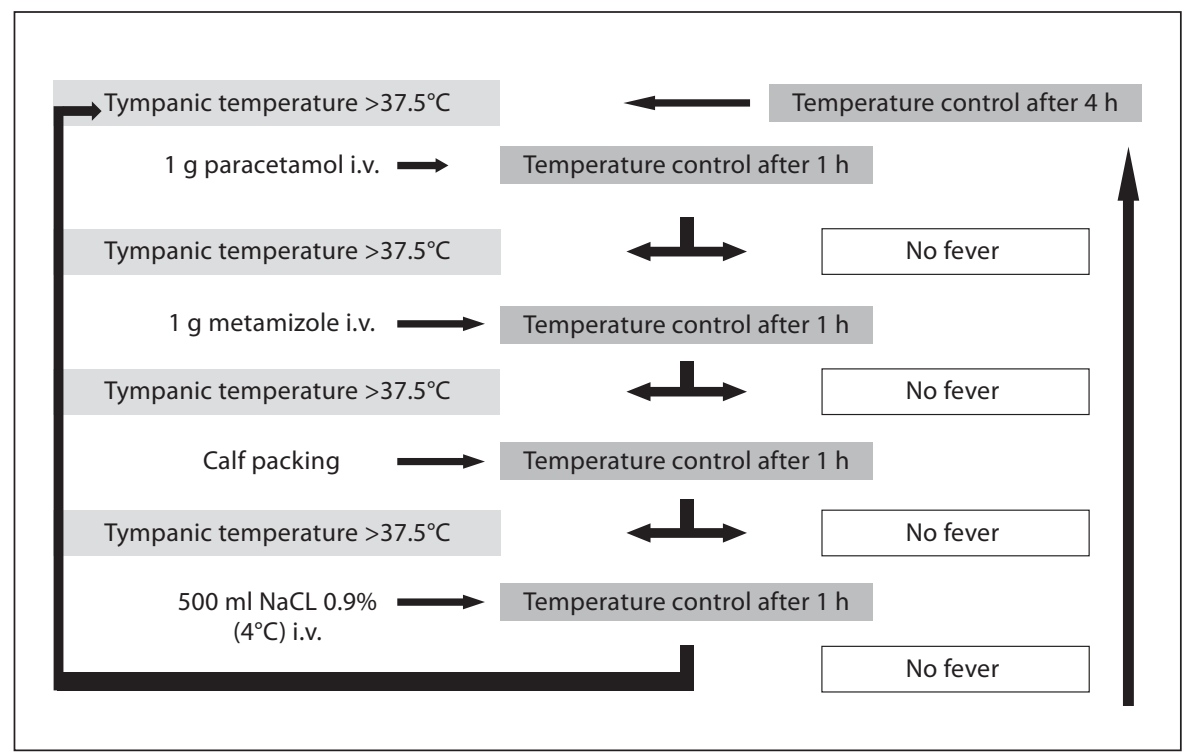

physical cooling, involving a total of 423 participants [8]. The pooled analysis revealed no impact on the risk of death or dependency. Twenty-four hours after treatment onset, the pharmacological strategies achieved a reduction in mean body temperature of $0.2^{\circ} \mathrm{C}$, and it was disputed whether this rather small effect has any clinical relevance at all. In a recently published trial, 1,400 patients received either $6 \mathrm{~g}$ of paracetamol per day or placebo, irrespective of the presence of fever [9]. There was a slight reduction in mean body temperature of $0.26^{\circ} \mathrm{C}(95 \%$ confidence interval $0.18-0.31$ ) but no significant advantage with regard to the functional outcome after 3 months.

In this study, we report the effect of an institutional standard operating procedure (SOP) for patients receiving treatment in a specialized stroke unit. Instead of a single-drug approach, the protocol used a sequence of 4 pharmacological and physical interventions. Sequential treatment strategies for fever have been described previously in different arrangements $[10,11]$, but to date their effects have never been investigated.

\section{Methods}

Standard Operating Procedure

A 4-step SOP was established and used at the Stroke Unit of the University Medical Center Erlangen-Nuremberg, Erlangen, Germany, for a period of 14 weeks from March to June 2009. The study was approved by the local ethics committee. Patients with cerebral ischemia (ischemic stroke, transient ischemic attack), hemorrhage (intracerebral, subarachnoidal) or cerebral sinus thrombosis and an increase in body temperature to $\geq 37.5^{\circ} \mathrm{C}$ within the first 6 days after admission were eligible for inclusion in the study. The diagnosis was confirmed by cranial imaging and focal clinical signs. At levels 1 and 2, patients received a single bolus of 1,000 mg of paracetamol and metamizole, respectively, through a peripheral or central intravenous line (fig. 1). In cases of nonresponse to antipyretic drugs, external cooling with calf packing was applied for $60 \mathrm{~min}$ at level 3, and finally an intravenous infusion of $500 \mathrm{ml}$ of cooled $\left(4^{\circ} \mathrm{C}\right)$ saline $(0.9 \% \mathrm{NaCl})$ over $30 \mathrm{~min}$ was performed at level 4 . The last step was reserved for patients without clinical signs of congestive heart failure or a history of dyspnea (NYHA III or IV). Measurement of body temperature was performed $60 \mathrm{~min}$ after the patient entered each level. Body temperature $\geq 37.5^{\circ} \mathrm{C}$ after completion of the last step resulted in a drop back to level 1 . The protocol procedure limited treatment to a maximum of 4 complete cycles within $24 \mathrm{~h}$. All patients received continuous noninvasive cardiac monitoring, including ECG, oxygen saturation, heart rate and arterial blood pressure. Routine laboratory tests including liver enzymes ( $\gamma$-glutamyl transpeptidase, glutamic oxaloacetic transaminase, glutamic pyruvate transaminase), C-reactive protein (CRP), leukocytes and electrolytes were performed on admission and at least once during the following 6 days in the stroke unit; in the case of significant abnormalities, they were taken daily. The screening for elevated body temperatures was performed using an electronic tympanic thermometer (Genius 2 Tympanic Thermometer; Tyco Healthcare Group, Mansfield, Mass., USA) at 4-hour intervals in both the study and the control group.

\section{Measurements}

The duration of body temperature $\geq 37.5^{\circ} \mathrm{C}$ per day as well as the body temperature before and $60 \mathrm{~min}$ after every single antipyretic intervention were measured, and the time intervals from the initiation of antipyretic treatment until achievement of normothermia or fever relapse were recorded. Significant drops in arterial blood pressure ( $>30 \%$ from baseline systolic value or to 
Table 1. Patients' baseline characteristics

\begin{tabular}{lccc}
\hline & $\begin{array}{c}\text { Study population } \\
(\mathrm{n}=77)\end{array}$ & $\begin{array}{c}\text { Control population } \\
(\mathrm{n}=77)\end{array}$ & p value \\
\hline Age, years & $70 \pm 14$ & $70 \pm 14$ & 0.827 \\
Females & $45(58)$ & $42(55)$ & 0.626 \\
Transient ischemic attack & $8(10)$ & $9(12)$ & $52(68)$ \\
Ischemic stroke & $52(68)$ & $13(17)$ & 0.063 \\
Intracerebral hemorrhage & $12(16)$ & $3(4)$ & 0.183 \\
Subarachnoidal hemorrhage & $3(4)$ & 0 & $0.005^{*}$ \\
Sinus thrombosis & $2(3)$ & $32(41)$ & 0.088 \\
Atrial fibrillation & $21(27)$ & $62(81)$ & 0.352 \\
Arterial hypertension & $68(88)$ & $35(45)$ & 0.396 \\
Hyperlipidemia & $51(66)$ & $5(6)$ & 0.894 \\
Active smoking & $11(14)$ & $21(27)$ & 0.511 \\
Diabetes mellitus & $26(34)$ & $2(3)$ & 0.278 \\
Persistent foramen ovale & $4(5)$ & $21(27)$ & 0.716 \\
History of stroke & $20(26)$ & $13(17)$ & 0.929 \\
Coronary artery disease & $16(21)$ & $6(8)$ & 0.41 \\
History of myocardial infarction & $10(13)$ & $4(5)$ & 0.031 \\
Peripheral artery disease & $5(6)$ & $6.0(0-21 ; 9)$ & 0.146 \\
Median NIHSS day 1 (range; IQR) & $6.5(0-21 ; 10)$ & 28 & 0.199 \\
White blood cell count at baseline $>10,000 / \mathrm{nl}$ & 28 & 38 & 0.584 \\
CRP at baseline $>5$ mg/l & 51 & $31 \pm 17$ & $24 \pm 14$ \\
GOT at baseline, U/l & $36 \pm 25$ & $70 \pm 119$ & \\
GPT at baseline, U/l & $27 \pm 22$ & $61 \pm 72$ & \\
GGT at baseline, U/l & & & \\
\hline & & & \\
\hline
\end{tabular}

The control group was matched to the study group for age, sex and NIHSS score on admission. Values represent numbers of patients, with percentages in parentheses, or means $\pm \mathrm{SD}$, except where otherwise indicated. $\mathrm{GOT}=$ Glutamic oxaloacetic transaminase; GPT = glutamic pyruvate transaminase; GGT $=\gamma$-glutamyl transpeptidase. * Significant difference between the two groups.

$<100 \mathrm{~mm} \mathrm{Hg}$ ) within $4 \mathrm{~h}$ after the start of treatment were also recorded. Further endpoints were the length of stay in the stroke unit and the National Institutes of Health Stroke Scale (NIHSS) score on discharge.

\section{Control Group}

The historic control group consisted of 77 patients admitted to the same institutional stroke unit 1 year earlier. The patients had a diagnosis of acute cerebral ischemia or hemorrhage and developed a body temperature $\geq 37.5^{\circ} \mathrm{C}$ within the first 6 days after admission. Body temperature was routinely measured at 4 -hour intervals with a tympanic thermometer in the same way as in the prospective group. Fever was treated following the recommendations of the European Stroke Organization guidelines [7] without adherence to a standardized protocol. Patients were matched with the study population for age ( \pm 5 years), sex and NIHSS score $( \pm 4)$ on admission.

\section{Statistical Analysis}

Statistical calculations were performed using the PASW 18 software package (SPSS Inc., Stanford, Calif., USA). The $\chi^{2}$ test was used for nominal data, and the Mann-Whitney signed rank test for nonparametric data. For normally distributed data, mean values and standard deviations were calculated and the Student $t$ test was applied. Body temperatures before and after antipyretic interventions were compared using the nonparametric paired-sample Wilcoxon test. For comparison of fever duration between the study and control groups, analysis of variance for repeated measures was performed. The between-subject factor was membership in the study or control group. To control for violations of the sphericity assumption, the Greenhouse-Geisser correction was used.

\section{Results}

\section{Patient Characteristics}

During the 14-week study period, 329 patients were treated at the Stroke Unit of the University Medical Center Erlangen. Of these patients, 190 had a diagnosis of acute cerebral ischemia, hemorrhage or sinus thrombosis, 77 of whom (40.5\%) had a body temperature of $\geq 37.5^{\circ} \mathrm{C}$ at least once during the first 6 days after admission and were included in the study. A total of 331 single antipyretic interventions were applied. All patients were 


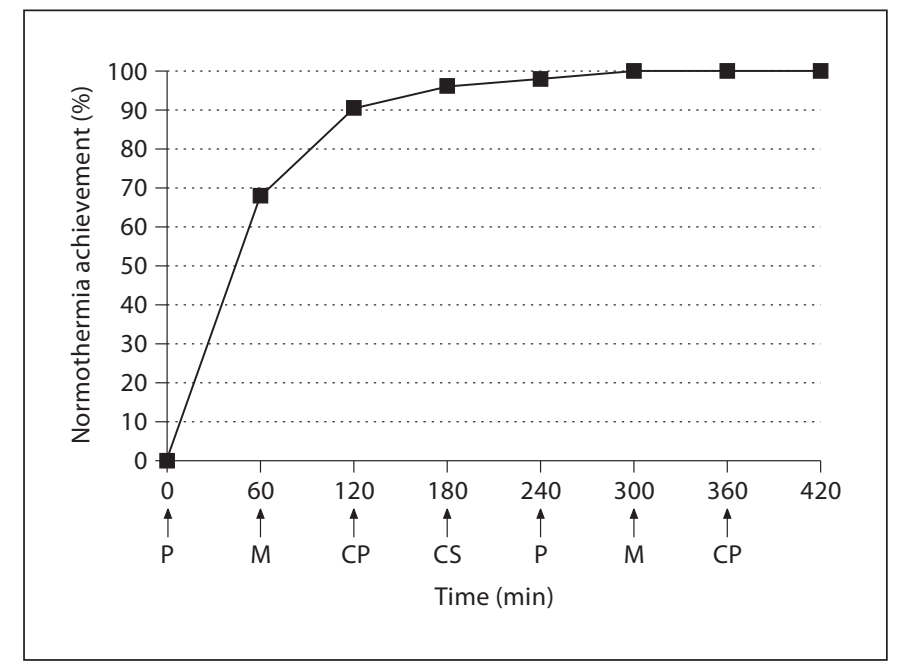

Fig. 2. Time course of normothermia achievement. The y-axis shows the proportion of patients (per-protocol population) who achieved treatment success (temperature $<37.5^{\circ} \mathrm{C}$ ). The $\mathrm{x}$-axis shows the time course after initiation of antipyretic treatment. The single interventions are shown in chronological sequence. $\mathrm{P}=$ Paracetamol $\mathrm{M}=$ metamizole $; \mathrm{CP}=$ calf packing $\mathrm{CS}=$ cooled saline (i.v.). Fever was treated successfully within $120 \mathrm{~min}$ in more than $90 \%$ of cases, and normothermia was achieved in all cases within $420 \mathrm{~min}$.

of Caucasian ethnicity; the mean age was $70 \pm 14$ years, and $58 \%$ were female. The median NIHSS score on day 1 was 6.5 [range $0-21$, interquartile range (IQR) 10]. The diagnosis of ischemic stroke was established in 52 patients $(68 \%)$, transient ischemic attack in 8 patients $(10 \%)$, intracerebral hemorrhage in 12 patients (16\%), subarachnoidal hemorrhage in 3 patients (4\%) and sinus thrombosis in 2 patients (3\%). Table 1 shows the baseline characteristics of the patients included in the study and the control group matched for age, sex and NIHSS score on admission.

\section{Prevalence of Fever and Infections}

Fever was evident in $35 \%$ of study patients on the first day after admission to the stroke unit and in $63 \%$ on the second day. During the clinical course, the proportion dropped to a minimum of $31 \%$ on day 5 . An increase in body temperature to $\geq 37.5^{\circ} \mathrm{C}$ with consecutive indication for antipyretic treatment was recognized 251 times. On admission, 51 patients (66.2\%) had CRP values $>5 \mathrm{mg} / \mathrm{dl}$, and in 28 patients (36.4\%), the white blood cell count was $>10,000 / \mathrm{nl}$. During treatment, an infectious focus was identified in 23 patients (29.8\%; pneumonia in 9 , urinary tract infection in 8 , various infections in 6 ).
Table 2. Prevalence of fever in the study and control groups during treatment in the stroke unit

\begin{tabular}{|c|c|c|c|c|}
\hline & \multicolumn{2}{|c|}{ Study group } & \multicolumn{2}{|c|}{ Control group } \\
\hline & $\begin{array}{l}\text { patients at } \\
\text { risk }\end{array}$ & $\begin{array}{l}\text { patients with } \\
\text { fever }(\%)\end{array}$ & $\begin{array}{l}\text { patients at } \\
\text { risk }\end{array}$ & $\begin{array}{l}\text { patients with } \\
\text { fever (\%) }\end{array}$ \\
\hline Day 1 & 77 & $27(35)$ & 77 & $31(40)$ \\
\hline Day 2 & 76 & $48(63)$ & 77 & $56(73)$ \\
\hline Day 3 & 75 & $38(51)$ & 75 & $60(80)$ \\
\hline Day 4 & 70 & $36(51)$ & 72 & $45(63)$ \\
\hline Day 5 & 51 & $16(31)$ & 61 & $35(57)$ \\
\hline Day 6 & 33 & $11(33)$ & 39 & $22(56)$ \\
\hline
\end{tabular}

The number of patients at risk decreased during the first days after admission due to discharge and in-hospital mortality. Absolute and relative numbers of patients with body temperatures $\geq 37.5^{\circ} \mathrm{C}$ within a period of $24 \mathrm{~h}$ are shown for day 1 to day 6 after admission.

Fever prevalence showed an analogous course in the historic control group (table 2). The rate of individuals in the control group with an elevated white blood cell count on admission was identical ( $\mathrm{n}=28 ; 36.4 \%)$, while fewer patients in the control group presented with CRP levels above the upper limit $(\mathrm{n}=38 ; 49.3 \%)$.

\section{Effects of Antipyretic Treatment}

The sequential application of paracetamol $(\mathrm{n}=219)$, metamizole $(\mathrm{n}=71)$ and calf packing $(\mathrm{n}=24)$ resulted in a significant drop in body temperature measured 60 min following the start of each intervention (table 3). After the infusion of cooled saline $(\mathrm{n}=9)$, a trend towards lower body temperatures was evident and patients became afebrile in $56 \%$ of cases. A second bolus of paracetamol was followed by normothermia in 3 of 5 cases and was associated with a significant drop in body temperature. Once a patient had achieved normothermia, fever relapsed early (within $24 \mathrm{~h}$ ) in $67 \%$ of cases. The median time to this early fever relapse ranged between 4 and $11 \mathrm{~h}$, depending on the last intervention applied (cooled saline and second bolus of paracetamol, respectively). The SOP led to normothermia $120 \mathrm{~min}$ after its initiation in more than $90 \%$ of cases and all patients in the per-protocol population were afebrile within $420 \mathrm{~min}$ (fig. 2). Compared to the control group, the overall duration of body temperature $\geq 37.5^{\circ} \mathrm{C}$ was considerably shorter in the study group during the first 4 days after admission (analysis of variance for repeated measures: $\mathrm{F}=60.9$; d.f. $\leq 1 / 140 ; \mathrm{p} \leq 0.001$; fig. 3 ). The 
Table 3. Effects of sequential antipyretic interventions $(n=331)$ in 77 febrile patients

\begin{tabular}{|c|c|c|c|c|c|c|c|}
\hline & Paracetamol & Metamizole & Calf packing & $\begin{array}{l}\text { Cooled } \\
\text { saline }\end{array}$ & $\begin{array}{l}\text { Paracetamol } \\
\text { (second } \\
\text { bolus) }\end{array}$ & $\begin{array}{l}\text { Metamizole } \\
\text { (second } \\
\text { bolus) }\end{array}$ & $\begin{array}{l}\text { Calf } \\
\text { packing } \\
\text { (second } \\
\text { time) }\end{array}$ \\
\hline Number of applications & 219 & 71 & 24 & 9 & 5 & 2 & 1 \\
\hline \multicolumn{8}{|l|}{ Median temperature before } \\
\hline intervention, ${ }^{\circ} \mathrm{C}(\mathrm{IQR})$ & $37.9(0.4)$ & $37.9(0.4)$ & $37.9(0.6)$ & $38.1(0.5)$ & $38.5(1.1)$ & 38.9 & 38.3 \\
\hline \multicolumn{8}{|l|}{ Median temperature after $60 \mathrm{~min}$} \\
\hline${ }^{\circ} \mathrm{C}(\mathrm{IQR})$ & $37.5(0.4)$ & $37.5(0.5)$ & $37.6(0.7)$ & $37.5(0.9)$ & $37.4(1.6)$ & 38.9 & 36.7 \\
\hline $\mathrm{p}$ value & 0.000 & 0.000 & 0.02 & 0.062 & 0.043 & - & - \\
\hline Normothermia achieved, n (\%) & $131(59.8)$ & $43(60.6)$ & $13(54.2)$ & $5(55.6)$ & $3(60)$ & 0 & 1 \\
\hline Early relapse $(<24 \mathrm{~h}), \mathrm{n}(\%)$ & $84(64.1)$ & $32(74.4)$ & $8(61.5)$ & $5(100)$ & $3(100)$ & 0 & 0 \\
\hline Median time to relapse, $\mathrm{h}$ (IQR) & $7.0(8.0)$ & $8.5(12.0)$ & $5.0(12.0)$ & $4.0(11.0)$ & 11.0 & - & - \\
\hline Antibiotic treatment, $\mathrm{n}(\%)$ & $154(70.3)$ & $55(77.5)$ & $19(79.1)$ & $9(100)$ & $5(100)$ & $2(100)$ & $1(100)$ \\
\hline
\end{tabular}

A statistically significant drop in body temperature resulted from the sequential administration of paracetamol, metamizole and calf packing. After the infusion of cooled saline, a trend towards lower temperatures was observed (paired-sample Wilcoxon test). The number of patients and the time intervals from the start of treatment are shown for normothermia achievement and fever relapse within $24 \mathrm{~h}$.

length of stay in the stroke unit was $5.88 \pm 2.8$ days for patients in the study group, while control patients spent on average $6.01 \pm 2.2$ days $(\mathrm{p}=0.404)$. The median NIHSS score on discharge was the same, i.e. $4.0(\mathrm{p}=$ 0.425 ), in the study group (range $0-23$, IQR 11 ) and in the control group (range $0-24, \mathrm{IQR} 7$ ).

\section{Drug Administration}

The mean daily doses of paracetamol never exceeded the upper limit of $4 \mathrm{~g} / \mathrm{day}$. In the control group, lower mean daily doses were administered and the differences were statistically significant on days $1,2,4$ and 5 ( $p<0.05$; fig. 4a). Similar results were found for metamizole. A total of 47 patients (61\%) in the study group received antibiotic treatment during their stay in the stroke unit, and the mean duration of antibiotic medication was $3.1 \pm 2.97$ days. A total of $74 \%$ of antipyretic interventions in the study group were applied under concomitant antibiotic treatment. Usage of antibiotic medication was lower in the control group (38\% of patients; mean duration $1.3 \pm$ 2.6 days; $\mathrm{p}=0.017)$.

\section{Safety Aspects}

Six patients in the study group (7.8\%) and 4 patients in the control group (5.2\%) died during their stay in hospital ( $\mathrm{p}=0.513)$. Their diagnosis on admission was ischemic stroke in 9 patients and intracerebral hemorrhage in 1 patient (control group). In the study group, death was attributable to space-occupying cerebral edema in 2 cases, to sepsis after infective endocarditis in 1 patient and to severe brain stem infarction in 1 patient. Two patients died from worsening heart failure as a result of acute myocardial infarction and long-term dilated cardiomyopathy, respectively. Neither patient was forwarded to level 4 of the treatment protocol. The proportions of patients with an increase in liver enzymes to more than 2.5 times the baseline value were not different between the groups (for glutamic pyruvate transaminase: 5 study patients vs. 7 control patients; $\mathrm{p}=$ 0.548). In 9 cases (4.7\%), a significant drop in systolic arterial blood pressure of more than $30 \%$ from the baseline value or below the cutoff $(100 \mathrm{~mm} \mathrm{Hg})$ occurred within $4 \mathrm{~h}$ after the initiation of antipyretic treatment. This was never associated with acute neurologic worsening or the need for intensive care. In all of these cases, paracetamol had been administered, 6 cases had additionally received metamizole and in 3 cases calf packing was applied. In 6 of these cases, the patient was receiving concomitant antihypertensive treatment. After the infusion of ice-cooled saline, 1 case of a new electrolyte imbalance was noticed $21 \mathrm{~h}$ after administration (sodium $128 \mathrm{mmol} / \mathrm{l}$ ). 


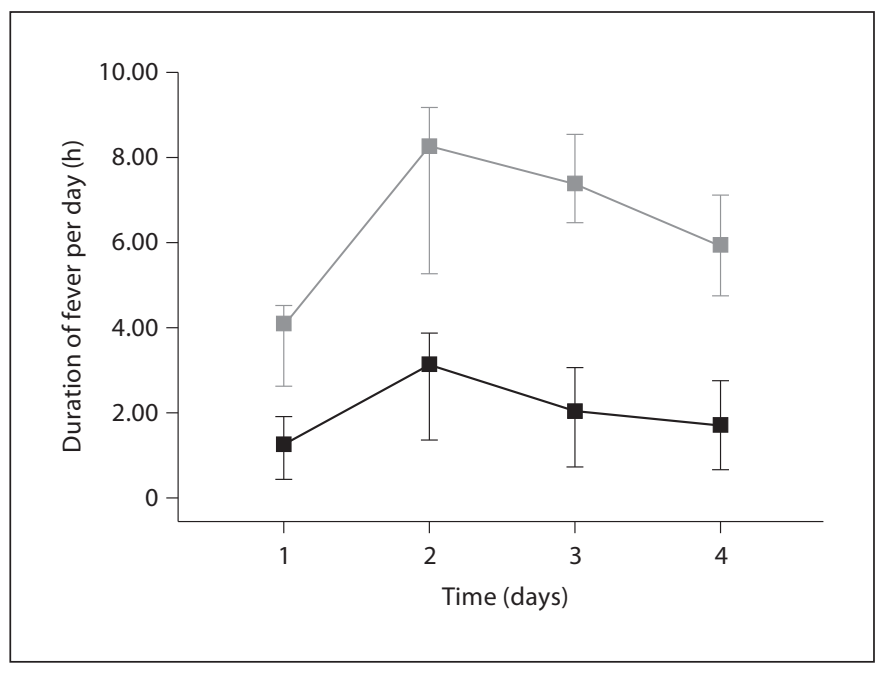

Fig. 3. Mean duration of body temperatures $>37.5^{\circ} \mathrm{C}$ in hours per day after admission to the stroke unit for the study group (black line) and the control group (gray line). Multivariate analysis of variance: $\mathrm{F}=60.9$; d.f. $=1 / 140 ; \mathrm{p} \leq 0.001$. Error bars indicate $95 \%$ confidence intervals.

\section{Discussion}

In this study, we report experiences with an SOP for fever treatment in patients suffering from acute cerebral ischemia, hemorrhage or sinus thrombosis. The incidence of fever was $40.5 \%$ within the first 6 days after admission. An infectious focus was identified in $29.8 \%$ of febrile patients. A total of 331 antipyretic interventions were applied. The sequential administration of paracetamol, metamizole and calf packing resulted in a significant drop in body temperature after $60 \mathrm{~min}$ in each instance. Infusion of ice-cooled saline was followed by normothermia in 5 of 9 cases that had been refractory to previous fever-lowering attempts. More than $90 \%$ of cases in the per-protocol population achieved normothermia within $120 \mathrm{~min}$. Compared to a historic control group that received conventional treatment, fever burden was remarkably lower, while the usage of antipyretic drugs had increased. However, the reduced fever burden did not translate into improved functional outcome on discharge or shorter length of stay.

Antipyretic treatment is being attributed a pivotal role in acute stroke care due to several reasons. Firstly, a strong association exists between fever in acute neurologic injury and increased morbidity and mortality $[1-3,5,6]$. Secondly, therapeutic hypothermia is being considered an effective neuroprotectant in animal experiments [12]
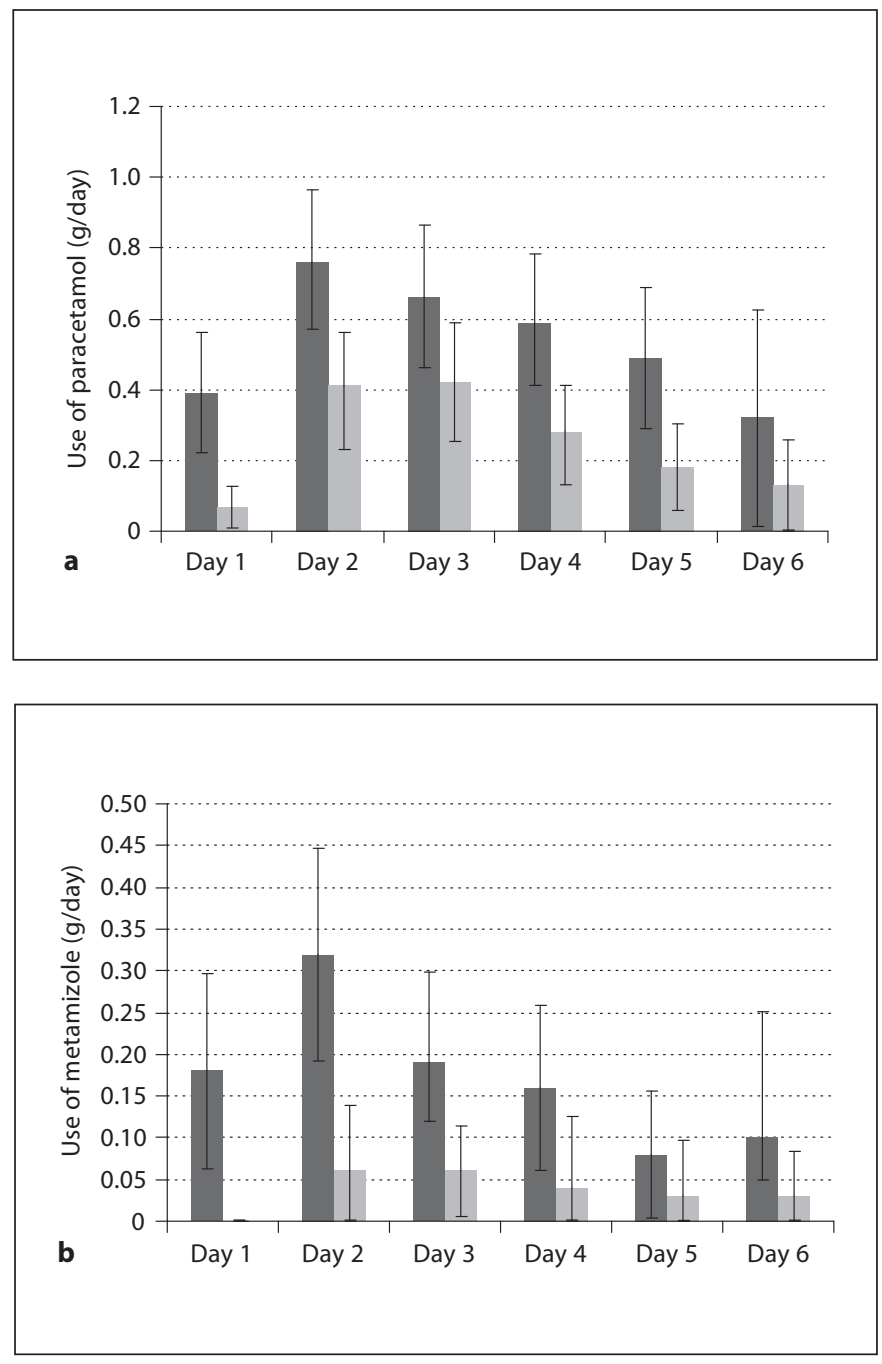

Fig. 4. Administration of paracetamol (a) and metamizole (b) shown as mean daily doses for the study group (dark-gray bars) and the control group (light-gray bars). Error bars indicate 95\% confidence intervals.

and patients after cardiac arrest [13]. However, at present there is uncertainty as to the optimal antipyretic strategy [14], and results from regimens published thus far, predominantly pharmacologic monotherapies, have been rather disappointing $[8,9,15]$. The post hoc results of the Paracetamol (Acetaminophen) In Stroke trial indicated an improvement in functional outcome as a result of antipyretic therapy in a subgroup of patients with elevated body temperatures at baseline [9]. In accordance with this finding, interventions in the present SOP were limited to patients with body temperatures $\geq 37.5^{\circ} \mathrm{C}$, while prophylactic treatment was not performed. 
A defined sequential combination of drugs within approved dosages and strategies applied in routine patient care was the basis for the SOP in this study. The safety assessment revealed an in-hospital mortality of $7.8 \%$ and liver function disturbances in $6.5 \%$ of patients. Values from the historic control group and from previously published investigations [16] were within the same ranges. Cases of a significant decrease in blood pressure (4.6\%) and electrolyte disturbances (1 case after the administration of cooled saline) were observed but were never associated with acute neurologic worsening or the need for intensive care.

There are several limitations of the present study. Screening for elevated body temperatures and the followup of treatment success were performed with an electronic tympanic thermometer. In critically ill patients, this method showed limited accuracy but was significantly correlated with temperatures derived from the gold standard (pulmonary artery catheter) [17]. Tympanic temperature measurement is noninvasive, easy, quick and broadly used in routine patient care. However, a mean difference of $\pm 0.36^{\circ} \mathrm{C}$ compared to invasively measured values should be taken into account when data are interpreted [18]. The control group consisted of patients who received nonstandardized fever treatment in the same institution 1 year earlier. The reliability of this approach is clearly inferior to a randomized, controlled trial. However, blinding to physical cooling methods $[19,20]$ and randomization to a parallel arm with conventional treatment on the same ward is unfeasible. Therefore, the comparison with the retrospective control group may be the best compromise to allow an estimation of differences in fever duration and drug usage. Although the patients' characteristics were well matched between the study and control groups, there were more subjects with elevated CRP levels at baseline and the use of antibiotic medication was more common in the study group. As a significant temperature-lowering effect of antibiotic treatment has been described previously [11], results from the between-group analysis must be interpreted with caution.

The present study investigated a standardized protocol for fever treatment in stroke patients, which included 4 different antipyretic interventions applied sequentially at intervals of $60 \mathrm{~min}$ until the body temperature was $<37.5^{\circ} \mathrm{C}$. As the single interventions may cumulate, comparison of their isolated efficacy is not possible. In consequence of that, the significant temperature-lowering effects described here cannot be transferred to clinical situations outside the SOP. No impact of the treatment regimen on the early functional outcome was detected, nor was the length of stay in the stroke unit significantly different. The latter may be an inappropriate parameter for the assessment of treatment effects, as it depends highly on the individual organization and the availability of rehabilitation care. Additional functional endpoints and long-term outcome measurement should be included in future trials.

\section{Conclusions}

This SOP may serve as a potent method to normalize body temperature towards normothermia and help to optimize antipyretic treatment for stroke patients.

\section{References}

1 Greer DM, Funk SE, Reaven NL, Ouzounelli M, Uman GC: Impact of fever on outcome in patients with stroke and neurologic injury: a comprehensive meta-analysis. Stroke 2008; 39:3029-3035.

2 Grau AJ, Buggle F, Schnitzler P, Spiel M, Lichy C, Hacke W: Fever and infection early after ischemic stroke. J Neurol Sci 1999;171: 115-120.

3 Hajat C, Hajat S, Sharma P: Effects of poststroke pyrexia on stroke outcome: a metaanalysis of studies in patients. Stroke 2000; 31:410-414.

4 Sulter G, Elting JW, Maurits N, Luijckx GJ, De Keyser J: Acetylsalicylic acid and acetaminophen to combat elevated body temperature in acute ischemic stroke. Cerebrovasc Dis $2004 ; 17: 118-122$.
5 Schwarz S, Hafner K, Aschoff A, Schwab S: Incidence and prognostic significance of fever following intracerebral hemorrhage. Neurology 2000;54:354-361.

6 Reith J, Jorgensen HS, Pedersen PM, Nakayama H, Raaschou HO, Jeppesen LL, Olsen TS: Body temperature in acute stroke: relation to stroke severity, infarct size, mortality, and outcome. Lancet 1996;347:422425.

7 European Stroke Organisation (ESO) Executive Committee; ESO Writing Committee: Guidelines for management of ischaemic stroke and transient ischaemic attack 2008. Cerebrovasc Dis 2008;25:457-507.
8 Den Hertog HM, van der Worp HB, Tseng MC, Dippel DW: Cooling therapy for acute stroke. Cochrane Database Syst Rev 2009; CD001247.

9 den Hertog HM, van der Worp HB, van Gemert HM, Algra A, Kappelle LJ, van Gijn J, Koudstaal PJ, Dippel DW: The Paracetamol (Acetaminophen) In Stroke (PAIS) trial: A multicentre, randomised, placebo-controlled, phase III trial. Lancet Neurol 2009;8: 434-440.

10 Broessner G, Beer R, Lackner P, Helbok R, Fischer M, Pfausler B, Rhorer J, KuppersTiedt L, Schneider D, Schmutzhard E: Prophylactic, endovascularly based, long-term normothermia in ICU patients with severe cerebrovascular disease: bicenter prospective, randomized trial. Stroke 2009;40:e657e665. 
11 Schwarz S, Al-Shajlawi F, Sick C, Meairs S, Hennerici MG: Effects of prophylactic antibiotic therapy with mezlocillin plus sulbactam on the incidence and height of fever after severe acute ischemic stroke: The Mannheim Infection in Stroke Study (MISS). Stroke 2008;39:1220-1227.

12 van der Worp HB, Sena ES, Donnan GA, Howells DW, Macleod MR: Hypothermia in animal models of acute ischaemic stroke: a systematic review and meta-analysis. Brain 2007;130:3063-3074.

13 Hypothermia after Cardiac Arrest Study Group: Mild therapeutic hypothermia to improve the neurologic outcome after cardiac arrest. N Engl J Med 2002;346:549-556.

14 Kallmunzer B, Beck A, Schwab S, Kollmar R: Antipyretic strategies for acute stroke: a nationwide survey among German stroke units (in German). Nervenarzt 2010;81:734-739.
15 Dippel DW, van Breda EJ, van der Worp HB, van Gemert HM, Meijer RJ, Kappelle LJ, Koudstaal PJ; PISA-Investigators: Effect of paracetamol (acetaminophen) and ibuprofen on body temperature in acute ischemic stroke PISA, a phase II double-blind, randomized, placebo-controlled trial [IS RCTN98608690]. BMC Cardiovasc Disord 2003;3:2.

16 Dippel DW, van Breda EJ, van Gemert HM, van der Worp HB, Meijer RJ, Kappelle LJ, Koudstaal PJ: Effect of paracetamol (acetaminophen) on body temperature in acute ischemic stroke: a double-blind, randomized phase II clinical trial. Stroke 2001;32:16071612.

17 Farnell S, Maxwell L, Tan S, Rhodes A, Philips B: Temperature measurement: comparison of non-invasive methods used in adult critical care. J Clin Nurs 2005;14:632-639.
18 Moran JL, Peter JV, Solomon PJ, Grealy B, Smith T, Ashforth W, Wake M, Peake SL, Peisach AR: Tympanic temperature measurements: are they reliable in the critically ill? A clinical study of measures of agreement. Crit Care Med 2007;35:155-164.

19 De Georgia MA, Krieger DW, Abou-Chebl A, Devlin TG, Jauss M, Davis SM, Koroshetz WJ, Rordorf G, Warach S: Cooling for Acute Ischemic Brain Damage (COOL AID): a feasibility trial of endovascular cooling. Neurology 2004;63:312-317.

20 Kammersgaard LP, Rasmussen BH, Jorgensen HS, Reith J, Weber U, Olsen TS: Feasibility and safety of inducing modest hypothermia in awake patients with acute stroke through surface cooling: a case-control study: the Copenhagen Stroke Study. Stroke 2000;31:2251-2256. 